\title{
CONTRIBUIÇÕES À MELHORIA DE PROCESSOS ORGANIZACIONAIS: UMA AVALIAÇÃO EMPÍRICA SOB A PERSPECTIVA DE MAPEAMENTO DE PROCESSOS EM UMA UNIDADE DA UNIVERSIDADE FEDERAL DA PARAÍBA
}

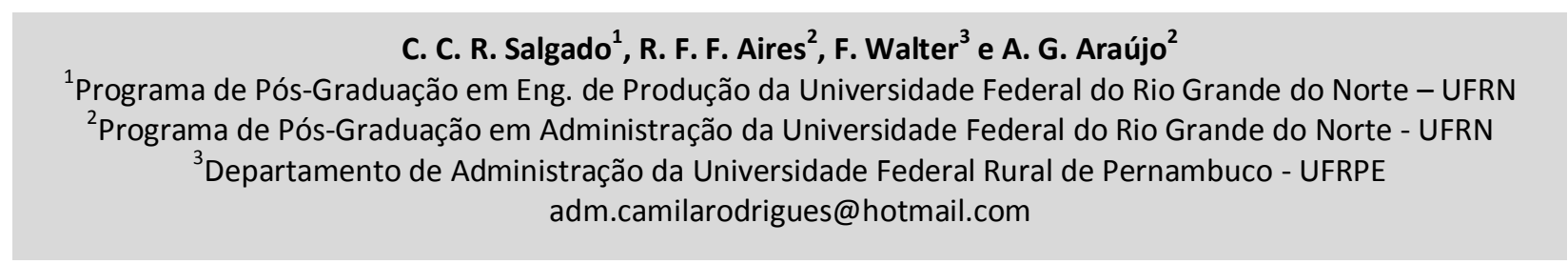

Artigo submetido em agosto/2012 e aceito em março/2013

\section{RESUMO}

O objetivo deste artigo é identificar, a partir do mapeamento de processos críticos, possíveis melhorias para a gestão da Coordenação do Curso de Administração (CCA) da Universidade Federal da Paraíba. Para tanto, realizou-se um estudo de caráter exploratório, descritivo e aplicado, que descreve os processos críticos da unidade estudada e analisa-os visando a sua melhoria. As técnicas de coleta de dados utilizadas foram a entrevista semiestruturada, o questionário, a matriz GUT (Gravidade/Urgência/
Tendência) e a observação simples. Como resultado, identificou-se que os processos de Matrícula e de Montagem das Blocagens eram os mais críticos, cujos principais problemas residiam na falha de comunicação entre a CCA e os departamentos acadêmicos, e a ausência de planejamento da oferta de disciplinas prevista. Assim, foi feita uma proposta de melhoria para o aperfeiçoamento dos processos organizacionais e foi constatada a importância do processo de mapeamento como ferramenta de melhoria contínua.

PALAVRAS-CHAVE: Melhoria de Processos, Mapeamento de Processos, Gestão de Instituições de Ensino Superior.

\section{CONTRIBUTIONS FOR THE IMPROVEMENT OF ORGANIZATIONAL PROCESSES: AN EMPIRICAL EVALUATION IN THE PERSPECTIVE OF PROCESS MAPPING IN A UNIT OF THE FEDERAL UNIVERSITY OF PARAÍBA}

\begin{abstract}
The objective of the article is to identify, from the mapping of critical processes, possible improvements to the management of the Course Coordination Administration (CCA) of the Federal University of Paraíba. For this purpose, we carried out an exploratory, descriptive and applied study, describing the critical processes of the unit studied and analyzes them with a view to its improvement. The techniques of data collection used were: semi-structured interview, questionnaire, the matrix GUT (Severity / Urgency /

Trend) and simple observation. As a result, we found that the process of Registration and Installation of Groupings were the most critical, the main problems reside in the failure of communication between the CCA and the academic departments, and the absence of planning the provision of courses provided. Thus, a proposal was made for the improvement of organizational processes and the importance of process mapping as a tool for continuous improvement was noted.
\end{abstract}

KEY-WORDS: Process Improvement, Process Mapping, Management of Institutions of Higher Education. 
CONTRIBUIÇÕES À MELHORIA DE PROCESSOS ORGANIZACIONAIS: UMA AVALIAÇÃO EMPÍRICA SOB A PERSPECTIVA DE MAPEAMENTO DE PROCESSOS EM UMA UNIDADE DA UNIVERSIDADE FEDERAL DA PARAÍBA

\section{INTRODUÇÃO}

As organizações, diante do cenário competitivo e exigente a que estão sujeitas, necessitam de ferramentas que as possibilitem obter resultados otimizados em seus processos. 0 aumento da competição, as mudanças crescentes das exigências dos stakeholders e novas tecnologias são os motores das transformações que obrigam as organizações a melhorarem seus processos (SEETHAMRAJU; MARJANOVIC, 2009). A administração deve estar preparada e deve ser constantemente repensada para quebrar paradigmas, tendo como premissas básicas a mudança evolutiva do pensamento administrativo dos profissionais da organização e o desenvolvimento de metodologias administrativas que sejam capazes de sustentar o processo de mudança evolutiva (OLIVEIRA, 2007).

Nesse sentido, a gestão de processos proporciona o apoio necessário à melhoria de processos empresariais. Estudá-los representa uma estratégia vencedora para se alcançar a sustentabilidade organizacional em ambientes de alta competitividade e alta volatilidade de vantagens competitivas (PORTER, 1999; BATEMAN, 2005; DALMARIS et al., 2007).

A gestão por processos é, de acordo com Rotondaro (2005), uma metodologia para avaliação contínua, análise e melhoria do desempenho dos processos, principalmente daqueles que são mais impactantes na satisfação dos seus clientes e stakeholders em geral. Segundo o autor, ela é marcada por um grande envolvimento de todos dentro da organização, o que pode resultar em uma melhor satisfação dessas pessoas no trabalho; agilidade no andamento das atividades; desenvolvimento de habilidades, bem como no aumento da autoridade e autonomia individual.

Instrumentos que levem ao caminho da melhoria contínua e dêem suporte para que as organizações alcancem ganhos em desempenho são bem-vindos, não só em organizações privadas, como também nas públicas. Segundo Santos (2006), uma organização pública é um sistema aberto, e que por isso, está em constante intercâmbio com o ambiente externo, além de ser constituído internamente de outros subsistemas, o que requer uma constante gestão dos seus principais processos diante da crescente exigência advinda da sociedade.

Há de se considerar ainda alguns aspectos a respeito da administração de processos nas instituições governamentais. O quadro caótico característico desse tipo de instituição pode revelar alguns fatores que dificultam a aplicação da administração de processos (OLIVEIRA, 2007), como a falta de profissionalismo dos servidores envolvidos, o fisiologismo dos representantes políticos, com influência direta na escolha de dirigentes do setor público, entre outros.

Neste contexto, as universidades públicas se apresentam como organizações complexas, principalmente no tocante à gestão de recursos e processos envolvidos, e que necessitam de um gerenciamento que possa proporcionar eficiência à realização de seus serviços, atendendo aos anseios e as exigências da sociedade por uma prestação de serviço com qualidade.

A Universidade Federal da Paraíba - UFPB caracteriza-se como um ambiente propício para aplicação da abordagem de gestão por processos, uma vez que precisa de resultados que 
proporcionem um melhor desempenho de suas atividades e que atendam aos interesses de seus stakeholders. Dessa forma, foi escolhida uma de suas unidades, a Coordenação do Curso de Administração (CCA), vinculada ao Centro de Ciências Sociais Aplicadas (CCSA), localizado no Campus I - João Pessoa, para a análise de processos organizacionais do presente artigo, através do mapeamento de seus processos críticos.

Portanto, o objetivo deste artigo foi identificar possíveis melhorias nos processos críticos da Coordenação do Curso de Administração da UFPB, a partir de seu mapeamento. Para tanto, este artigo está estruturado da seguinte forma: em primeiro lugar discute sobre a gestão de instituições de ensino superior, abordando a importância da busca pela qualidade e melhoria neste setor; depois aborda a gestão de processos, tecendo breves considerações acerca do tema; em seguida discute sobre o mapeamento de processos, apresentando uma breve definição do termo e abordando a técnica do fluxograma; depois são apresentados, respectivamente, os procedimentos metodológicos e os resultados; e finalmente, tece a conclusão do estudo, relatando as principais inferências obtidas no estudo, relacionadas aos processos críticos, à aplicabilidade da gestão por processos em instituições públicas e as sugestões de trabalhos futuros.

\section{GESTÃO DE INSTITUIÇÕES DE ENSINO SUPERIOR}

As instituições de ensino superior, especialmente as universidades federais, são complexas e tem como função básica, a indissolubilidade do ensino, pesquisa e extensão e a consequente oferta de produtos e serviços que possam contribuir para a melhoria da qualidade de vida da sociedade (BOLZAN, 2006; MAGALHAES et al., 2010). Como geradora de conhecimentos e saberes, as instituições de educação superior brasileiras, em particular as universidades, têm enfrentado constantes desafios de gestão e de busca de formas mais eficientes e eficazes de atuação provocados por mudanças no ambiente. Entre os motivadores da mudança estão aspectos relacionados à política educacional, as demandas do setor produtivo, as flutuações na demanda por cursos e as renovadas necessidades e expectativas dos alunos (MEYER JÚNIOR; PASCUCCI; MANGOLIN, 2012).

Segundo Bolzan (2006), no ambiente interno das universidades, a busca pela qualidade é um dos caminhos trilhados pela gestão para melhorar os processos acadêmicos e administrativos como contribuição à solução dos graves problemas que envolvem a gestão universitária.

Logo, fica claro que a busca por melhorias, que antes era apenas uma preocupação do setor privado, passa a preocupar também o setor público, que se viu submetido a uma maior pressão para melhorar seu desempenho e demonstrar maior transparência e avaliação de resultados (BIAZZI; MUSCAT; BIAZZI, 2011).

Um aspecto motivador para a adoção da qualidade no setor público pode ser o auxílio à organização quanto à identificação de suas oportunidades de melhoria (RADIN; COFFEE, 1993). Além disso, outro aspecto seria a própria exigência da sociedade, que busca saber o destino dos recursos direcionados às universidades, assim como o seu desempenho (VENTURINI et al., 2010).

Apesar disto, segundo Biazzi, Muscat e Biazzi (2011), são raros os autores que apresentam modelos para aperfeiçoamento de processos no setor público. Portanto, o uso de ferramentas que auxiliem as instituições públicas no processo de melhoria contínua é um meio valioso de qualificação de processos destas. 


\section{GESTÃO POR PROCESSOS}

A partir de uma visão macro, Harrington (1993, p. 34) diz que "os processos são as atividades-chave necessárias para administrar e/ou operar uma organização". Na perspectiva de Anjard (1998), o processo é composto por uma série de atividades de agregação de valor que produza uma saída para um cliente, sendo estes todos aqueles que recebem a saída do processo. Uma terceira visão é a de Kipper et al. (2011), em que um processo pode ser entendido como a introdução de insumos (entradas) em um ambiente formado por procedimentos, normas e regras que, ao processarem os insumos, transformam-se em resultados que serão enviados aos clientes do processo (saída).

Percebe-se que, apesar de similares, parece não haver uma definição de processo única que seja a mais amplamente utilizada. Em um estudo de revisão de literatura, Palmberg (2009) encontrou que entre as definições identificadas de acordo com vários autores, seis componentes principais estariam ligados a conceituação de processo: (1) entradas e saídas (inputs e outputs); (2) atividades inter-relacionadas; (3) alinhamento horizontal: intra-funcional ou cross-funcional; (4) finalidade ou valor para o cliente; (5) utilização dos recursos; e (6) repetibilidade.

A gestão por processos é uma importante forma de lidar com o desafio da melhoria dos processos de uma organização para a otimização de seu desempenho (TRKMAN, 2010). Ela aponta que é necessário que ocorram mudanças na forma de se gerenciar as organizações e, uma delas é que os processos e os subprocessos passem a ser orientados com base nos requisitos dos clientes, tanto o externo quanto o interno, ou seja, os processos e as melhorias são orientadas pelos clientes externos, enquanto que cada subprocesso orienta-se com base nos requisitos dos clientes internos que recebem suas saídas (VARVAKIS et al., 1998).

Em suma, a ideia principal da gestão por processos é desenvolver uma organização voltada para processos por meio da eliminação de atividades que não agregam valor ao negócio (KUJANSIVU; LONNQVIST, 2008), de forma a identificar oportunidades de melhoria da qualidade e do desempenho operacional da organização, visando à satisfação dos seus clientes (FRASER et al., 2013).

Sobre isso, quando se questiona qual o propósito da gestão por processos, uma das respostas apresentadas por Palemberg (2009) é que esta tem a finalidade de controlar e melhorar os processos da organização, e que uma das vertentes de pensamento dos autores em relação ao foco da gestão por processos seria a de uma sistemática e estruturada abordagem para analisar e melhorar continuamente o processo. Assim, de forma geral, a gestão por processos permite às empresas compartilhar informações rapidamente e contribui para manter os seus empregados em uma curva ascendente de aprendizado (AMARAL et al., 2011).

Além disso, é de grande importância para as organizações que buscam a melhoria em seus processos que considerem a importância da criticidade dos mesmos. Identificar os processos críticos é direcionar os esforços para as atividades que necessitam de aperfeiçoamento. Em conformidade com isto, Aldowaisan e Gaafar (1999) afirmam que uma empresa para melhorar seu desempenho deve, em primeiro lugar, identificar as suas operações críticas, que são as que afetam mais diretamente a qualidade. Complementando esse raciocínio, Carreira (2009) e Rotondaro (2005) afirmam que o estudo de racionalização de processos deve ser iniciado pelos processos críticos já que assim os resultados serão mais significativos, enfatizando também que a questão da identificação desses processos não é tarefa fácil. 
Sobre isso, Varvakis et al. (1998) destacam que os processos críticos podem ser encontrados ou representados a partir de aspectos ligados à magnitude do impacto no desempenho global da empresa; à facilidade de modificação; ou até mesmo, àqueles que não apresentam resistência interna a modificações. Ou seja, sua definição não segue um modelo preciso e depende de cada organização. Surge então a necessidade de mapeamento desses processos, para que eles sejam conhecidos com detalhes e oportunidades de melhorias sejam identificadas.

\section{MAPEAMENTO DE PROCESSOS}

A maioria dos processos de uma organização são formalmente documentados, muitos deles através de procedimentos operacionais padrão (POP), baseados principalmente na experiência dos servidores. Apesar de toda validade desta prática, isto já não é suficiente hoje em dia, pois a requisição atual é mais voltada para uma apresentação gráfica, ou seja, por um mapeamento de processos (ZABJEK; KOVACIC; STEMBERGER, 2009), que, de acordo com Pyon, Woo e Park (2011), é uma premissa básica da gestão por processos.

Segundo Biazzo (2000), construir um mapa de processos significa realçar, graficamente, num modelo, a relação entre as atividades, pessoal, informações e objetos envolvidos. Além disso, segundo Carpinetti (2000), a partir do contexto de desdobramento de melhorias, o mapeamento dos processos tem por objetivo tornar mais explícita a relação entre dimensões de desempenho e atividades primárias ou de suporte desenvolvidas pela empresa para o atendimento de seus clientes, sendo essas representações fundamentais para entender não apenas processos isolados, mas também o fluxo de informação e recursos através dos processos operacionais e processos de suporte da cadeia interna de valor.

Portanto, o mapeamento de processos é essencial para entender o fluxo de valor à medida que cria uma compreensão mais profunda das atividades no processo. $O$ resultado importante disso é a lista de áreas de melhoria que podem ser encontradas (JULIEN; TJAHJONO, 2009). Para coletar as informações necessárias para a elaboração de um mapeamento, podem ser feitas entrevistas com os responsáveis pelo processo na organização, visando identificar todas as atividades executadas pela gerência, seus responsáveis e suas interações (KIPPER et al., 2011).

Existem algumas técnicas para representação das atividades de um processo. Dentre os instrumentos citados na literatura, os fluxogramas são os mais utilizados e constituem um elemento-chave para o aperfeiçoamento de processos, pois destacam áreas que afetam a qualidade e facilitam as comunicações entre as áreas problemáticas (HARRINGTON, 1993). Este recurso visual representa, através de símbolos gráficos, a sequência de determinado trabalho, o que facilita sua análise e contribui para a identificação de oportunidades para melhorar sua eficiência (PEINADO; GRAEML, 2007). De forma geral, os fluxogramas mostram o modo como as coisas são feitas, e não o modo que é dito pela chefia aos servidores, ou seja, eles revelam a realidade das coisas, são uma fotografia da situação real (OLIVEIRA, 1998).

\section{PROCEDIMENTOS METODOLÓGICOS}

O presente artigo pode ser classificado como: exploratório, descritivo e aplicado. Exploratório porque não objetiva a elaboração de hipóteses a serem testadas no trabalho, 
restringindo-se a definir objetivos e buscar mais informações sobre determinado assunto estudado (CERVO; BERVIAN; SILVA, 2006); descritivo, pois descreveu os processos críticos da unidade organizacional, ou seja, teve como principal objetivo a descrição de algo (MALHOTRA, 2001); e aplicado porque objetivou gerar conhecimentos para aplicação prática à solução de problemas específicos, envolvendo verdades e interesses locais (SILVA; MENEZES, 2001).

As estratégias de pesquisa utilizadas no artigo foram à pesquisa documental, pois foram utilizados documentos de dentro da organização (MARTINS, 2004); pesquisa bibliográfica, devido às fontes pesquisadas no desenvolvimento teórico do artigo (MALHOTRA, 2001); e estudo de caso, pois estudou em profundidade uma unidade organizacional específica (YIN, 2005).

O ambiente da pesquisa foi a Coordenação do Curso de Administração (CCA) da Universidade Federal da Paraíba (UFPB), localizada no Centro de Ciências Sociais Aplicadas (CCSA) - Campus I (João Pessoa). Os sujeitos da pesquisa, que são as pessoas que fornecem os dados necessários, foram os servidores da CCA (seis no total - quatro assistentes administrativos, um auxiliar em assuntos educacionais e um coordenador).

As técnicas de coleta de dados utilizadas foram: entrevista semiestruturada; questionário; matriz GUT (Gravidade/Urgência/Tendência); e observação simples. Inicialmente, foi aplicada a entrevista semiestruturada com todos os servidores da CCA para identificar e obter informações aprofundadas sobre os processos da unidade em estudo.

Depois do levantamento dos processos, foi utilizada a Matriz GUT, que é uma técnica utilizada para identificar possíveis processos cujas saídas (outputs) estão aquém do desejado, interferindo na eficiência máxima daquele processo (VARVAKIS et al., 1998). Esta técnica utiliza o tripé composto por gravidade, urgência e tendência para priorização de problemas ou processos. Assim, a Matriz GUT foi utilizada junto aos sujeitos da pesquisa para identificar quais dentre os processos levantados eram críticos, e que, portanto, deveriam ser priorizados no mapeamento. Para aplicação desta técnica foi utilizado como apoio um questionário que auxiliou no levantamento das pontuações dadas pelos sujeitos da pesquisa quanto aos aspectos da matriz (gravidade, urgência e tendência).

Em outra fase, também foi utilizada a observação simples, que proporcionou aos pesquisadores uma visão realista do funcionamento dos processos da CCA, observando de perto o andamento das atividades, sem influenciá-las, para compreender melhor como ocorriam os procedimentos da mesma.

Para a análise dos processos críticos foram criados fluxogramas, utilizando o programa Visio, versão 2007, da Microsoft que utiliza o padrão ANSI - AMERICAN NATIONAL STANDARDS INSTITUTE de simbologia, fornecendo uma compreensão detalhada do processo (HARRINGTON, 1993).

Finalmente, para a identificação de melhorias nos processos críticos da CCA, foi utilizado na análise de dados, a técnica de melhoria de processos proposta por Mischak (1997) apresentada na Figura 1, que proporciona contribuições significativas para a organização estudada. 


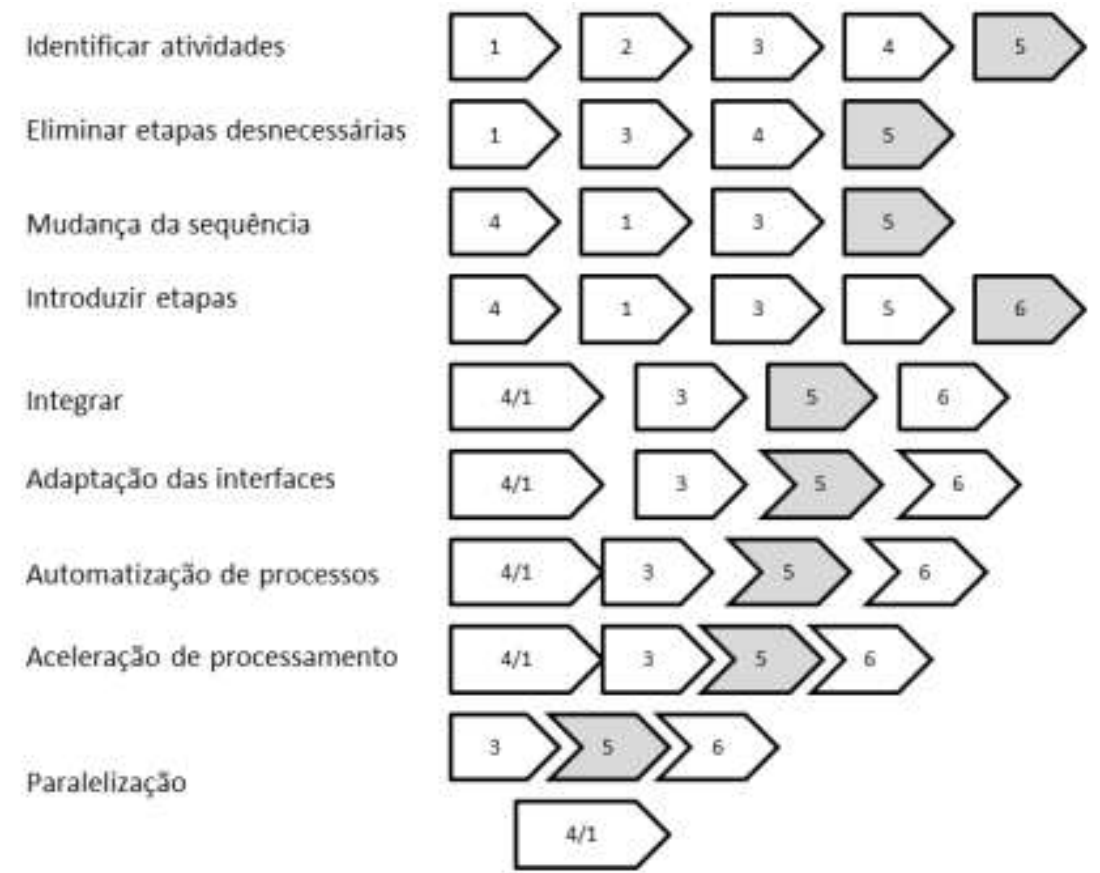

Figura 1: Procedimentos de melhoria de processos. Fonte: Mischak (1997).

Segundo este autor, os processos podem ser otimizados através de muitos procedimentos, especialmente em relação às etapas e ferramentas utilizadas para a "racionalização" dos processos. Assim, exemplificando uma das formas possíveis de melhoria de processos apresentadas na Figura 1, se existem atividades duplicadas, uma delas deve ser eliminada (ou até mesmo as duas, se elas não forem realmente necessárias), de modo a reduzir os custos e o tempo de ciclo.

\section{RESULTADOS}

\section{IDENTIFICAÇÃO DOS PROCESSOS EXISTENTES}

O primeiro passo para alcançar os objetivos do presente artigo, foi a realização do levantamento dos processos da CCA através de uma entrevista semiestruturada aplicada junto aos servidores da mesma. A entrevista resultou na identificação dos seguintes processos: Matrícula; Equivalência e Dispensa; Trancamento; Revisão de Prova; Emissão de Certificados de Conclusão de Curso; Emissão de Declarações; Emissão de Horários; Verificação de Cumprimento da Carga Horária; Encaminhamento de Atestados; Processo de Colação de Grau; Emissão de Ofícios; Processo de Dilatação de Prazo do Curso; Encaminhamento de Alunos para Estágio; Reuniões do Colegiado; Elaboração de Memorandos; Informações Gerais ao Público; Processos Referentes ao PIANI; Recepção aos Calouros; Solicitação de Material e Montagem das Blocagens.

\section{IDENTIFICAÇÃO DOS PROCESSOS CRÍTICOS}

Após a identificação dos processos da CCA foram aplicados questionários a seis servidores desta, com um total de nove questões cada, que apresentava todos os processos identificados e os questionava sobre: a gravidade dos processos ("Na sua opinião, qual dos processos listados 
tem a maior/média/menor gravidade?" - 3 questões); a urgência dos processos ("Na sua opinião, qual dos processos listados tem a maior/média/menor urgência em ser solucionado?" - 3 questões); e tendência ("Na sua opinião, qual dos processos listados tem a maior/média/menor tendência a piorar?" - 3 questões). A partir dos resultados obtidos nos questionários, a avaliação foi realizada de acordo com os seguintes pesos: os processos apontados como mais graves, com maior urgência em ser solucionados e maior tendência a piorar receberam peso 5; já os processos indicados como de média gravidade, média urgência em ser solucionados e tendência média a piorar receberam peso 3; e finalmente, os processos apontados como de menor gravidade, menor urgência de ser solucionados e menor tendência a piorar receberam peso 1. Logo, somando-se os valores obtidos nos três aspectos (gravidade, urgência e tendência) para cada processo em questão, chegou-se à ponderação total de cada processo e a uma ordem de importância que indica quais processos devem ser tratados primeiro, representada pela Matriz GUT.

A partir da Matriz GUT elaborada (Tabela 1), foi possível observar que os processos que obtiveram a maior ponderação e, consequentemente, classificam-se como críticos são os seguintes: Matrícula e Montagem das Blocagens. Os dois processos alcançaram a somatória de 56 e 35 pontos, respectivamente. O terceiro colocado (solicitação de material) aparece com apenas 14 pontos e uma considerável distância dos primeiros.

Tabela 1: Matriz GUT dos processos da CCA

\begin{tabular}{|c|c|c|c|c|}
\hline \multirow{2}{*}{ Processo } & \multicolumn{3}{|c|}{ Votos } & \multirow{2}{*}{ Total } \\
\cline { 2 - 4 } & $\mathrm{G}$ & $\mathrm{U}$ & $\mathrm{T}$ & \\
\hline Matrículas & 18 & 20 & 18 & 56 \\
\hline Montagem das blocagens & 16 & 8 & 11 & 35 \\
\hline Solicitação de Material & 3 & 3 & 8 & 14 \\
\hline Reuniões do Colegiado & 3 & 4 & 1 & 8 \\
\hline Processo de Trancamento & 1 & 4 & 1 & 6 \\
\hline Emissão de Horários & 3 & - & 1 & 4 \\
\hline Encaminhamento de Alunos para Estágio & - & - & 3 & 3 \\
\hline Revisão de Prova & - & 3 & - & 3 \\
\hline Recepção aos Calouros & 1 & 1 & - & 2 \\
\hline Informações Gerais ao Público & - & 1 & - & 1 \\
\hline Elaboração de Memorandos & - & 1 & - & 1 \\
\hline Dilatação de Prazo do Curso & - & - & 1 & 1 \\
\hline Emissão de Ofícios & - & - & 1 & 1 \\
\hline
\end{tabular}

Fonte - Elaboração dos Autores.

Vale ressaltar que dos vinte processos identificados anteriormente, apenas quatorze processos receberam votação dos servidores e estão listados na matriz GUT, porém todos os vinte estavam expostos no momento da votação.

\section{ANÁLISE DOS PROCESSOS CRÍTICOS}

Visando analisar os processos críticos da CCA, foram elaborados fluxogramas que descrevem os processos de Matrícula, bem como a Montagem das Blocagens. Na análise dos dois processos é possível observar que eles são de grande impacto para o cliente; são de grande 
abrangência, já que suas melhorias se estenderiam por toda organização; têm certo grau de dificuldade por depender de diversos fatores, como o relacionamento com outros organismos da UFPB, e necessitam de recursos para a implementação da melhoria e para a manutenção do novo processo.

Os dois processos têm uma forte interrelação, já que a Montagem das Blocagens é o procedimento que antecede a matrícula que é disponibilizada aos discentes. Dessa forma, apesar do processo de Matrícula ter sido eleito o mais crítico, a próxima seção irá mapear primeiramente o processo de Montagem das Blocagens.

\subsection{PROCESSO “MONTAGEM DAS BLOCAGENS”}

A Montagem das Blocagens refere-se à elaboração de todo o quadro do período letivo, contendo as disciplinas ofertadas, seus créditos, códigos das turmas, os respectivos horários, número de turmas e as respectivas salas de aula.

Esse processo se inicia com a montagem do quadro da blocagem por período pela CCA, tanto para o turno diurno quanto para o noturno. Além disso, essa montagem leva em consideração as disciplinas ofertadas para o currículo antigo (1995) e para o currículo novo (2007) do curso de Administração. A elaboração desse quadro é feita com base nos períodos anteriores e a partir da negociação com outros departamentos.

Com o quadro da blocagem pronto, a CCA encaminha memorandos com as blocagens montadas a serem avaliadas para os departamentos envolvidos, são eles: Departamento de Administração; Departamento de Economia; Departamento de Ciências Contábeis; Departamento de Matemática; Departamento de Estatística; Departamento de Ciência da Informação; Departamento de Ciências Sociais; Departamento de Psicologia; Departamento de Filosofia; Departamento de Direito; Departamento de Comunicação Social; Departamento de Letras Estrangeiras e Modernas; e Departamento de Letras Clássicas e Vernáculas.

Após essa fase, os departamentos analisam a blocagem enviada verificando as disciplinas em relação à disponibilidade dos docentes e de seus horários. Se as blocagens enviadas forem aprovadas, os departamentos as inserem no Sistema de Controle Acadêmico (SCA) e a CCA imprime o "pijama" (quadro das blocagens por período, por turno e de acordo com o currículo antigo e currículo novo dos horários). O SCA é responsável pela gestão das atividades acadêmicas dos professores, alunos e servidores com relação ao cadastramento de notas, emissão de históricos, relatórios estatísticos, gerenciamento dos cursos entre outras operações. Todas as informações inseridas nesse sistema são recolhidas pela CODESC (Coordenação de Escolaridade) posteriormente, em um período específico para que as blocagens possam ser disponibilizadas online no site da UFPB e assim, os discentes possam efetuar a matrícula.

Caso a blocagem enviada não seja aprovada pelos departamentos, por exemplo, quando algum docente não tem disponibilidade para o horário que lhe foi reservado, os departamentos enviam à CCA as modificações necessárias. A partir daí, a CCA faz a alteração da blocagem da(s) disciplina(s) modificada(s) e, posteriormente, ao final dessa negociação, imprime o "pijama" das ofertas. Vale ressaltar que essa troca de informações se dá via memorando, via telefônica e via Sistema de Controle Acadêmico.

Em seguida, a CCA confere o "pijama" final com os horários a serem divulgados e depois o encaminha para a Assessoria de Graduação do CCSA com as salas definidas para que seja feita a 
alocação das salas de aula. A Assessoria de Graduação do CCSA realiza então a alocação das salas de aula e a insere no Sistema de Controle Acadêmico, encerrando o processo de Montagem das Blocagens. Caso o "pijama" dos horários não seja aprovado após a CCA conferi-lo, ou seja, caso as informações estejam desencontradas, a CCA altera novamente a blocagem da(s) disciplina(s) modificada(s) e imprime o "pijama" das ofertas dando continuidade ao processo até o seu término.

A grande questão desse processo, e que segundo os servidores da CCA faz com que ele se classifique como crítico está no fato de que a comunicação entre os departamentos é falha, principalmente quando se trata do Departamento de Administração, pois este oferece a maior parte das disciplinas.

O Departamento de Administração, que é o responsável por implantar e confirmar as informações no Sistema de Controle Acadêmico, realiza modificações em algumas disciplinas e algumas vezes não comunica a alteração à CCA. Por isso, o horário montado pela CCA e que é disponibilizado aos alunos não condiz com as informações contidas no Sistema de Controle Acadêmico, podendo ocorrer vários choques. Em alguns casos essas modificações ultrapassam o prazo permitido pela CODESC para alterações nas blocagens e muitas vezes chegam a ocorrer na semana de matrículas, gerando tumultos na CCA, desencontro de informações e atraso do início das disciplinas.

Ainda em relação à comunicação entre os departamentos, os memorandos enviados pela CCA solicitando à confirmação das ofertas das disciplinas, muitas vezes não são respondidos e confirmados, atrasando o andamento do processo.

Outra questão importante é que a Assessoria de Graduação do CCSA solicita o "pijama", ou seja, o horário das disciplinas ofertadas para realizar a distribuição das salas de aula, e algumas vezes o recolhe mesmo sem que ele esteja finalizado. Por isso, se houver alguma modificação nas blocagens a assessoria não é informada, podendo resultar em choques de disciplinas alocadas para uma mesma sala de aula.

O processo de Montagem das Blocagens encontra ainda como dificuldade em sua realização, o fato de que o curso de Administração ainda está em fase de transição de Currículos. É preciso montar as blocagens considerando que algumas disciplinas do currículo antigo (1995) estão sendo extintas, porém existem alguns alunos que por diferentes razões atrasam o curso e inviabilizam essa extinção. Nessa montagem, a CCA não realiza um planejamento se baseando na quantidade de alunos blocados e fora das blocagens, não tendo uma previsibilidade de quais disciplinas precisam de mais ou menos vagas.

\subsection{PROCESSO “MATRÍCULA”}

A blocagem elaborada no processo anterior é recolhida pela CODESC em prazos específicos via Sistema de Controle Acadêmico, e disponibilizada para os discentes através do sistema de matrículas no site da UFPB para que a matrícula seja efetuada.

O processo se inicia com a efetuação da matrícula no endereço eletrônico "https://www.ufpb.br/AutoServico/discente.html" pelos alunos, em seus períodos específicos. Caso a matrícula seja efetuada com sucesso, o processo se encerra, caso contrário, o discente procura a CCA para efetuá-la no período de ajuste. É importante citar que o período de matrículas tem momentos específicos para alunos calouros, para alunos por blocagem, para 
alunos não blocados e para os alunos especiais, e o período de ajustes compreende a primeira semana de aulas regulares.

A matrícula dos alunos calouros é realizada automaticamente pela PRG/CODESC/NTI (PróReitoria de Graduação/Coordenação de Escolaridade/Núcleo de Tecnologia da Informação) e caso o horário do aluno não apresente a listagem completa das disciplinas, ele deve procurar a Coordenação para esclarecimentos e ajustes (UFPB, 2012a). Há ainda o período específico de matrícula no site da UFPB para alunos blocados, que são os que foram aprovados em todas as disciplinas do semestre letivo imediatamente anterior e cujos componentes curriculares correspondem ao semestre letivo ideal, cursado sem reprovação, dispensa e/ou trancamento (UFPB, 2012a). Já a matrícula dos alunos não blocados ocorre pelo mesmo endereço eletrônico e é para os alunos em geral que não se enquadrem nas classes anteriores. Além disso, vale destacar que o limite de créditos para realização da matrícula é de no mínimo 16 créditos, o que equivale a 4 disciplinas da grade curricular.

No período de ajustes, o aluno analisa e escolhe a(s) disciplina(s) que pretende matricular com base no "pijama" de horários disponibilizados pela CCA e requisita pessoalmente na CCA a realização da matrícula. A CCA então verifica se o aluno é blocado, se existe vaga para a(s) disciplina(s) requisitada(s) e se ela(s) depende $(\mathrm{m})$ de algum pré-requisito. Se o aluno atender as exigências para a efetuação da matrícula, a CCA a efetua, caso contrário, verifica-se se existe alguma outra disciplina que possa ser matriculada. Se houver essa possibilidade, o aluno volta para a fase de análise e escolhe disciplinas a serem matriculadas. Quando não existe esta possibilidade, verifica-se se existe algum processo de abertura de turma extra, e caso haja, o aluno assina uma lista de interessados na abertura dessa turma, aguarda o processo, e em caso de abertura a CCA efetua a matrícula do aluno e o processo se encerra. Se não houver possibilidade de abertura de turma extra, o processo também se encerra, pois não há outro mecanismo disponível.

Vale salientar a existência de casos especiais. São considerados casos especiais: aguardo de pré-requisito; aproveitamento de estudos; concluinte; pré-concluinte; graduados; estrangeiros; de CONSEPE (Conselho Superior de Ensino, Pesquisa e Extensão); ex-officio; mandado judicial; PIANI (Programa de Mobilidade Internacional); e PSTV (Processo Seletivo de Transferência Escolar Voluntária). Nestes casos, a CCA encaminha memorandos à CODESC solicitando a efetuação da matrícula. Após essa fase, a CODESC efetua a matrícula dos casos especiais que atendam aos períodos e requisitos estipulados e o processo se encerra.

Sobre os problemas existentes neste processo, tem-se que o sistema de informação utilizado pela UFPB para a realização das matrículas tem se mostrado falho. De acordo com as palavras do coordenador da CCA, esse sistema tem capacidade para 2000 acessos por minuto, porém atende a $\mathbf{2 8 . 0 0 0}$ alunos, tornando-se insuficiente nos períodos de matrícula onde a procura pelo serviço é maior. Dessa forma, os alunos, ao tentarem efetuar a matrícula através do site da UFPB, muitas vezes não conseguem o acesso e se dirigem pessoalmente à CCA para efetuar 0 ajuste, gerando grandes aglomerados em seu ambiente.

Outro fato importante na execução da matrícula é que os alunos muitas vezes não se planejam com antecedência e chegam à coordenação no período de ajuste sem saber quais disciplinas vão optar ou o(s) código(s) da(s) disciplina(s) desejada(s), atrasando o atendimento, gerando reclamações e criando filas.

Além disso, há um grande número de alunos fora da blocagem que têm certa dificuldade em encontrar vagas disponíveis para efetuar a matrícula. Geralmente esses alunos procuram à 
CCA para efetuar a matrícula e quando não há mais vagas eles incluem seus nomes em uma lista de interessados na(s) disciplina(s), para que, se houver a abertura de turmas extras, eles sejam matriculados. Esse processo se torna mais complexo e demorado quando não há professores ou salas de aula disponíveis, exigindo negociações entre os departamentos e a Assessoria de Graduação do CCSA, responsável pela alocação das salas de aula, atrasando o início da(s) atividade(s) da disciplina(s).

Ainda nesse sentido, esses alunos que inseriram seus nomes nas listas de interessados em turmas extras, em alguns casos, são matriculados pela CCA e não são avisados. Por isso, se eles não verificarem seus horários no espaço destinado para os alunos no site da UFPB ou até na própria CCA, eles correm o risco de serem reprovados por falta por não comparecerem na(s) aula(s) da(s) disciplina(s) matriculada(s).

\section{MELHORIA DOS PROCESSOS CRÍTICOS}

A partir da análise dos fluxogramas montados e de discussões com os servidores da CCA foi possível perceber a forte ligação que os dois processos eleitos como críticos possuem. Como dito anteriormente, a Montagem das Blocagens é o procedimento que antecede a realização da Matrícula e, por isso, se o primeiro processo não for realizado da melhor forma, consequentemente haverá problemas no segundo. As melhorias aqui sugeridas orientaram-se nos procedimentos esquematizados por Mischak (1997).

\subsection{MELHORIA PARA O PROCESSO “MONTAGEM DAS BLOCAGENS”}

Como dito anteriormente, a questão problemática desse processo está relacionada com a comunicação entre os departamentos e, a partir da análise das etapas do processo, identificou-se que a mais importante para o resultado, inclusive na visão dos servidores, é a confirmação das blocagens pelos departamentos. Se um departamento atrasa a resposta ou faz alguma modificação no horário de alguma disciplina, por exemplo, devido à disponibilidade de determinado professor, a CCA tem que fazer a alteração na blocagem completa, atingindo outros departamentos e gerando mais negociações, o que atrasa o andamento do processo. Por isso, sugere-se que seja cobrada dos departamentos a resposta dos memorandos, inclusive com novos memorandos, padronizando o processo.

É de extrema importância que a CCA, juntamente com o Departamento de Administração, que oferta o maior número de disciplinas, passe a realizar um planejamento mais elaborado das demandas, com base nos períodos anteriores e nos relatórios gerados pela Pró-Reitoria de Graduação (PRG) que indicam quantos alunos foram aprovados ou reprovados e, consequentemente, quantos estão blocados ou fora da blocagem, para que as blocagens sejam alocadas da maneira correta e para que se evitem conflitos e informações equivocadas, dificultando a realização do processo seguinte (Matrícula). Dessa forma, propõe-se que seja acrescentada na execução do processo a fase de planejamento da quantidade de turmas a serem ofertadas, principalmente utilizando-se dos relatórios gerados pela PRG. A sequência sugerida para o processo de Montagem das Blocagens pode ser visualizada na Figura 2. 


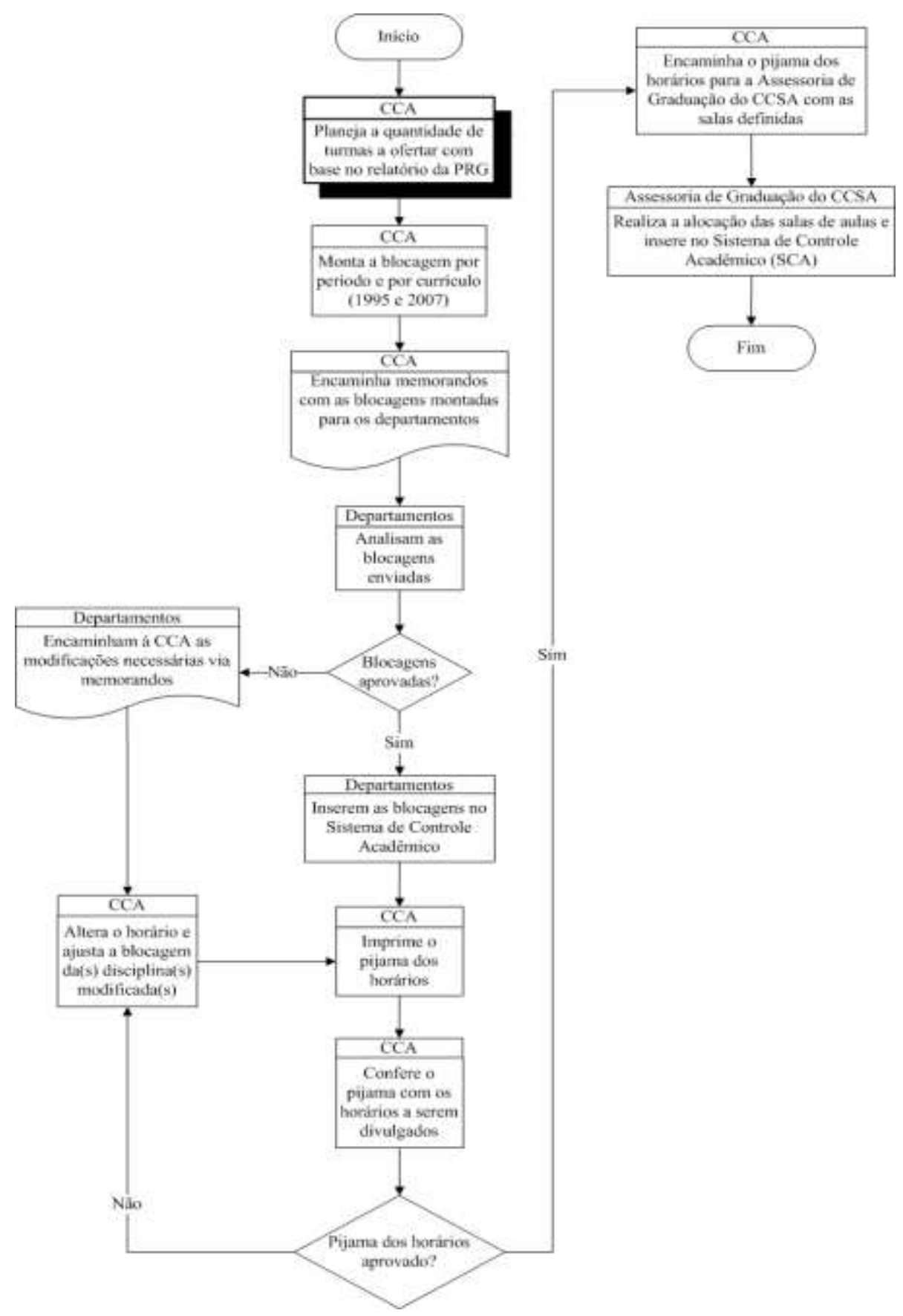

Figura 2: Fluxograma melhorado do processo “Montagem das Blocagens" Fonte - Elaboração dos Autores.

Com esse planejamento garante-se que seja ofertado o número de turmas capazes de atender a demanda e evitam-se problemas posteriores no período de matrículas. Esses ganhos podem ser vistos com mais ênfase na seção a seguir.

Vale salientar, que a CCA, na época da coleta de dados, não realizava esse planejamento e levantamento da quantidade de alunos blocados ou fora da blocagem, para então montar a oferta de disciplinas, porque não tem mão-de-obra suficiente. Dessa forma, sugere-se que seja contratado um novo servidor, principalmente para o horário noturno, que conta com apenas um servidor, para que as atividades sejam melhor definidas e distribuídas, ou, sugere-se ainda, que se realize algum treinamento específico com os servidores já existentes na CCA, para que seja 
possível realizar o planejamento/levantamento da quantidade de alunos blocados e fora da blocagem.

\subsection{MELHORIA PARA O PROCESSO “MATRÍCULA”}

Como ressaltado anteriormente, o processo de Matrícula está altamente relacionado ao processo de Montagem das Blocagens. Com a melhoria sugerida para este último, o processo de Matrícula obterá muitos ganhos (Ver figuras 3 e 4).

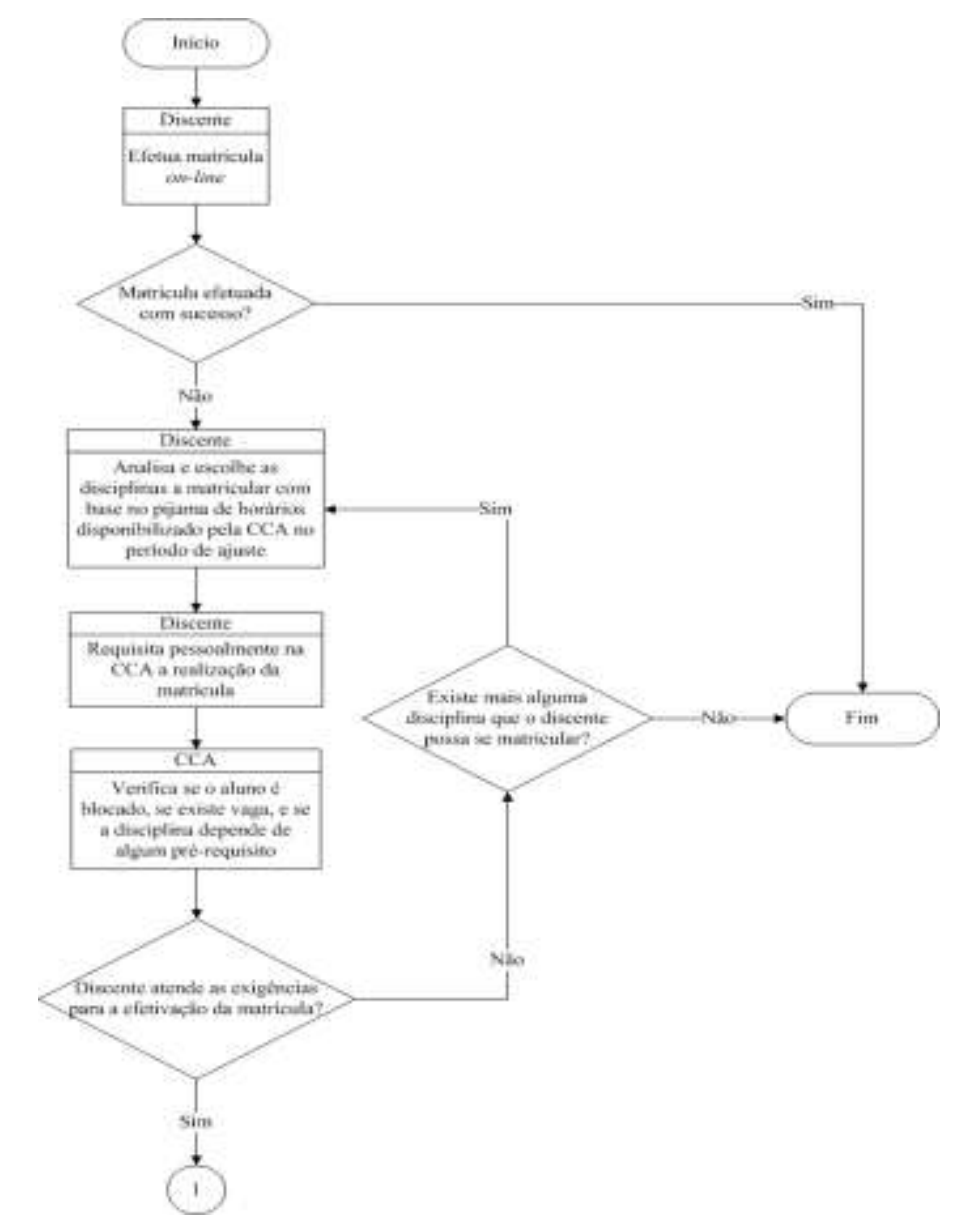

Figura 3: Fluxograma melhorado do processo de Matrícula - Parte I Fonte - Elaboração dos Autores. 


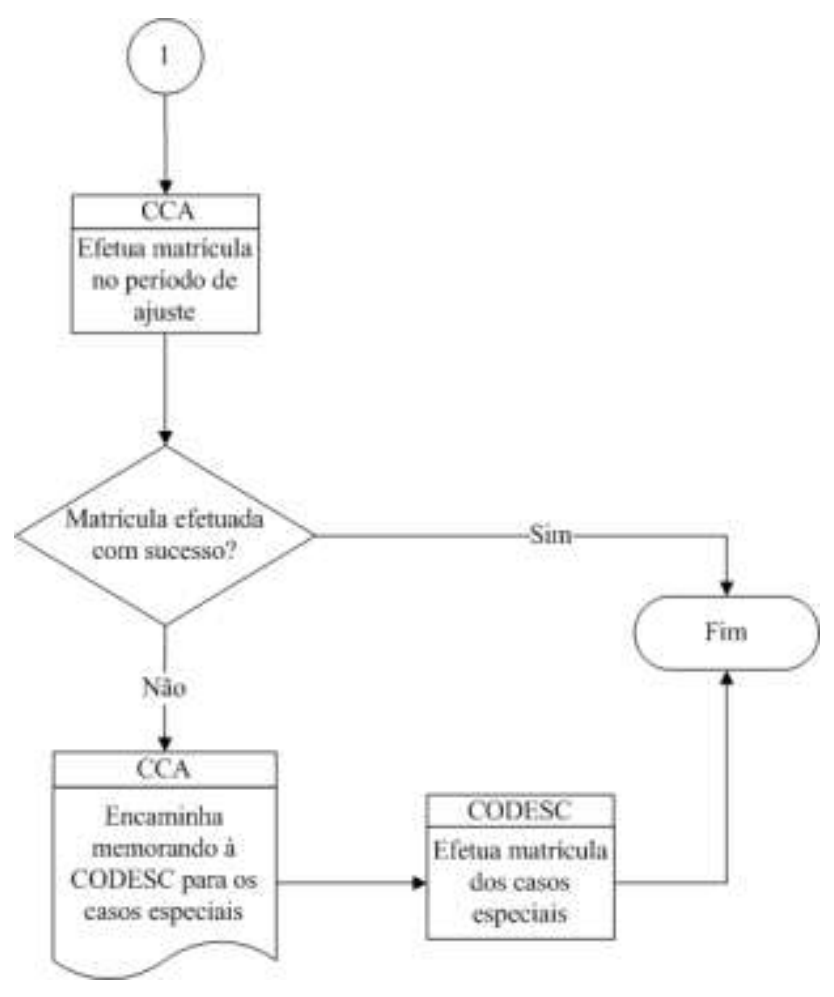

Figura 4: Fluxograma melhorado do processo de Matrícula - Parte II Fonte - Elaboração dos Autores.

Sobre esses ganhos, primeiramente, tem-se que se o número de disciplinas ofertadas (a partir do planejamento) for capaz de atender a demanda, os alunos terão suas matrículas efetuadas com sucesso ainda no site da UFPB, sem precisar procurar à CCA, o que diminui as filas e tumultos no ambiente da coordenação. Ainda nesse sentido, o planejamento evita que sejam criadas as listas de alunos interessados na abertura de turmas extras e que haja o atraso do início das atividades da(s) disciplina(s).

É possível observar que a partir do planejamento feito na Montagem das Blocagens seria possível eliminar atividades relacionadas à abertura de turmas extras, evitando situações desagradáveis já anteriormente citadas.

Além disso, visando solucionar o problema de alunos que procuram à CCA sem ter noção das disciplinas que pretendem optar ou dos códigos para efetuar a matrícula, sugere-se que a CCA disponibilize o "pijama" dos horários com os códigos das turmas com antecedência no site da UFPB, na área destinada à CCA, e no quadro de avisos localizado na parte externa da coordenação, para que assim os alunos possam se programar e o processo ganhe maior agilidade.

\section{CONCLUSÃO}

Neste artigo buscou-se identificar possíveis pontos de melhoria nos processos críticos da Coordenação do Curso de Administração da UFPB a partir do mapeamento de processos. Esta metodologia é uma oportunidade de melhoria para as organizações já que as permite conhecer seus processos detalhadamente e proporciona uma visão das relações entre as atividades e suas sequências, o que servirá de referência para correções, contribuindo com seu aperfeiçoamento. 
Após apresentação teórica acerca da gestão de Instituições de Ensino Superior, Gestão por Processos e Mapeamento de Processos foram identificados os processos da CCA, sendo estes, posteriormente, priorizados de acordo com sua criticidade na ótica dos servidores. Os processos críticos priorizados foram "Matrícula" e "Montagem das Blocagens", os quais foram mapeados com a utilização de fluxogramas.

A partir dos fluxogramas gerados, foi possível inferir que os processos críticos eleitos têm uma forte relação e seus mapeamentos proporcionaram uma visão ampla de como as atividades acontecem. Identificou-se que o processo de Matrícula, alvo de tantas reclamações, na verdade tem a origem de seu problema no processo que o antecede, o processo de Montagem das Blocagens. Essa montagem é dificultada devido à comunicação falha entre a CCA e os departamentos e traz consequências para a realização do processo de Matrícula, como o desencontro de informações, grandes filas no período de ajustes, atraso no início das atividades. Além disso, é importante citar que a presença dos atores de cada atividade dentro do processo no mapeamento foi de grande valor, já que eles conhecem com detalhes como o trabalho é realmente executado.

Através das propostas apresentadas nesse estudo, a CCA poderá agilizar o andamento dos dois processos críticos, eliminando atividades que dificultam e atrasam o resultado final. Os resultados alcançados a partir do planejamento das disciplinas a serem ofertadas e de uma melhor comunicação entre a CCA e os departamentos podem alcançar tanto os servidores desta coordenação, quanto os alunos assistidos por ela.

Portanto, tendo em vista os resultados obtidos neste artigo, pode-se concluir que a gestão por processos pode ser aplicada em instituições públicas, trazendo benefícios para organização. Finalmente, trabalhos futuros podem dar continuidade à discussão aqui realizada com a utilização de técnicas diferentes e outras abordagens de melhoria nessa e em outras instituições. Assim, as principais sugestões para trabalhos futuros, considerando que este estudo teve sua aplicação em um exemplo típico de unidade presente em todas as instituições de ensino superior públicas e os benefícios a serem sugeridos poderiam eventualmente ser replicados ou adaptados nos diversos órgãos semelhantes, são: mapear os demais processos da unidade estudada; comparar processos similares em outros cursos da UFPB; replicar o estudo em outros setores ou organizações.

\section{REFERÊNCIAS BIBLIOGRÁFICAS}

1. ALDOWAISAN, T.A.; GAAFAR, L.K. Business process reengineering: an approach for process mapping. Omega, v. 27, n. 5, p. 515-24, 1999.

2. AMARAL, C. S. T.; ROZENFELD, H.; COSTA, J. M. H.; MAGON, M. F. A.; MASCARENHAS, Y. M. Improvement of radiology services based on the process management approach. European Journal of Radiology, v. 78, n. 3, p. 377-383, 2011.

3. ANJARD, R. Process mapping: a valuable tool for construction management and other professionals. Facilities, v. 16, p. 79-81, 1998.

4. BATEMAN, N. Sustainability: the elusive element of process improvement. International Journal of Operations \& Production Management, v. 25, p. 261-276, 2005.

5. BIAZZO, S. Approaches to business process analysis: a review. Business Process Management Journal, v. 6, p. 99-112, 2000. 
6. BIAZZI, M. R; MUSCAT, A. R. N.; BIAZZI, J. L. Modelo de aperfeiçoamento de processos em instituições públicas de ensino superior. Gestão \& Produção, v. 18, n. 4, p. 869-880, 2011.

7. BOLZAN, C. I. M. Excelência em Gestão Universitária: Um Estudo de Caso em uma Instituição Federal de Ensino Superior. Dissertação (Mestrado em Engenharia da Produção) - Curso de Pós-Graduação em Engenharia de Produção, UFSM. Santa Maria. 2006.

8. CARREIRA, D. Organização, sistemas e métodos: ferramentas para racionalizar as rotinas de trabalho e a estrutura organizacional da empresa. 2. ed. São Paulo: Saraiva, 2009.

9. CARPINETTI, L. C. R. Proposta de um modelo conceitual para o desdobramento de melhorias estratégicas. Gestão \& Produção, v. 7, n. 1, p. 29-42, 2000.

10. CERVO, A. L.; BERVIAN, P. A.; SILVA, R. Metodologia Científica. 6 ed. São Paulo: Pearson Prentice Hall, 2006.

11. DALMARIS, P.; TSUI, E.; HALL, B.; SMITH, B. A framework for the improvement of knowledgeintensive business processes. Business Process Management Journal, v. 13, p. 279-305, 2007.

12. FRASER, K.; TSENG, B.; HVOLBY, H. TQM in new car dealerships: a study from the firms perpective. The TQM Journal, v. 25, n. 1, p. 5-17, 2013.

13. HARRINGTON, H. J. Aperfeiçoando processos empresariais. São Paulo: Makron Books, 1993.

14. JULIEN, D. M.; TJAHJONO, B. Lean thinking implementation at a safari park. Business Process Management Journal, v. 15, p. 321-335, 2009.

15. KIPPER, L. M.; ElLWANGER, M. C.; JACOBS, G.; NARA, E. O. B.; FROZZAS, R. Gestão por processos: Comparação e análise entre metodologias para implantação da gestão orientada a processos e seus principais conceitos. Tecno-Lógica, v. 15, n. 2, p. 89-99, 2011.

16. KUJANSIVU, P.; LONNQVIST, A. Business process management as a tool for intellectual capital management. Knowledge and Process Management, v. 15, n. 3, p. 159-169, 2008.

17. MAgAlhaES, E. A.; SILVEIRA, S. F. R.; ABRANTES, L. A.; FERREIRA, M. A. M.; WAKIM, V. R. Custo do ensino de graduação em instituições federais de ensino superior: o caso da Universidade Federal de Viçosa. Revista de Administração Pública, v.44, n.3, p. 637-666, 2010.

18. MALHOTRA, N. K. Pesquisa de marketing: uma orientação aplicada. 3. ed. Porto Alegre: Bookman, 2001.

19. MARTINS, R. B. Metodologia científica: como tornar mais agradável a elaboração de trabalhos acadêmicos. Curitíba, PR: Juruá, 2004.

20. MEYER JR, V.; PASCUCCI, L.; MANGOLIN, L. Gestão estratégica: um exame de práticas em universidades privadas. Revista de Administração Pública, v. 46, n. 1, p. 49-70, 2012.

21. MISCHAK, R. F. 'Business Reengineering - Der Weg vom funktions- zum prozeßorientierten Denken im Unternehmen'. In: Berndt, R. (ed.) Business Reengineering: effizientes Neugestalten von Geschäftsprozessen. Berlin: Springer. p. 3-17, 1997.

22. OLIVEIRA, D. P. R. Administração de Processos: conceitos, metodologia, práticas. 2. ed. São Paulo: Atlas, 2007. 
23. OLIVEIRA, D. P. R. Sistemas, organizações e métodos: uma abordagem gerencial. 10. ed. São Paulo: Atlas, 1998.

24. PALMBERG, K. Exploring process management: are there any widespread models and definitions?. The TQM Journal, v. 21, p. 203-215, 2009.

25. PEINADO, J.; GRAEML, A. R. Administração da produção: operações industriais e de serviços. Curitiba: UnicenP, 2007.

26. PORTER, M. Vantagem competitiva: criando e sustentando desempenho superior. 4. ed. Rio de Janeiro: Campus, 1999.

27. PYON, C. U.; WOO, J. Y.; PARK, S. C. Service improvement by business process management using customer complaints in financial service industry. Experts Systems with Applications, v. 38, p. 3267-3279, 2011.

28. RADIN, B. A.; COFFEE, J. N. A critique of TQM: problems of implementation in the public sector. Public Administration Quartely, v. 17, n. 1, p. 42-54, 1993.

29. ROTONDARO, R. G. Gerenciamento por processos. In: CARVALHO, M. M. de; PALADINI, E. P. (Org). Gestão da qualidade: teoria e casos. Rio de Janeiro: Elsevier, 2005.

30. SANTOS, C. S. Introdução à gestão pública. São Paulo: Saraiva, 2006.

31. SEETHAMRAJU, R.; MARJANOVIC, O. Role of process knowledge in business process improvement methodology: a case study. Business Process Management Journal. v. 15, p. 920-936, 2009.

32. SILVA. E. L.; MENEZES. E. M. Metodologia da Pesquisa e Elaboração de Dissertação. 3. ed. Florianópolis: LED/UFSC, 2001.

33. TRKMAN, P. The critical success factors of business process management. International Journal of Information Management, v. 30, p. 125-134, 2010.

34. UFPB - UNIVERSIDADE FEDERAL DA PARAÍBA. Pró-Reitoria de Graduação. Edital PRG/N 009/2011. Disponível em: <http://www.prg.ufpb.br/aluno_on_line.html> Acesso em: 23 mar. 2012a.

35. UFPB - UNIVERSIDADE FEDERAL DA PARAÍBA. Regimento Geral. Disponível em: <http://www.ufpb.br/sods/secretaria/regpage.htm> Acesso em: 25 mar. 2012b.

36. VARVAKIS, G. J. et al. Gerenciamento de Processos. Apostila da disciplina Gerenciamento de Processos e Variável Ambiental - PPGEP UFSC, 1998.

37. VENTURINI, J. C.; PEREIRA, B. A. D.; MORALES, R.; FLECK, C. F.; BASTISTELLA JR, Z.; NAGEL, M. B. Percepção da avaliação: um retrato da gestão pública em uma instituição de ensino superior (IES). Rev. Adm. Pública, v. 44, n. 1, p. 31-53, 2010

38. YIN, R. K. Estudo de caso: planejamento e métodos. 3. ed. Porto Alegre: Bookman, 2005.

39. ZABJEK, D.; KOVACIC, A; STEMBERGER, M. I. The influence of business process management and some other CSFs on successful ERP implementation. Business Process Management Journal, v. 15, p. 588 - 608, 2009. 